\title{
A COGNITIVE APROACH TO THE ROLE OF BODY PARTS IN THE CONCEPTUALIZATION OF EMOTION METAPHORS ${ }^{1}$
}

\author{
Sandra Peña Cervel \\ UNED. Madrid
}

\section{ABSTRACT}

This paper attemps to offer a basic blueprint for the analysis of metaphors for emotions and some realted abstract constructs which exploit body parts in their source domains. We adopt the well-known cognitive linguistics framework, in which metaphor is understood as a way of understanding and reasoning about the world (see Johnson, 1987; Lakoff, 1987; Lakoff \& Johnson, 1980, 1999; Lakoff \& Turner, 1989). As observed by Kövecses (1986, 1990, 1991), emotions, like other abstract concepts such as pain or trouble, are hard to conceptualize unless we make use of metaphor and image-schemas, among other cognitive models. In this paper, we provide further evidence in this respect. In order to do so, we shall first distinguish between prototypical and less prototypical body parts in the conceptualization of emotions. Secondly, we shall distinguish

I Financial support for this research has been pprovided by the DGES, Spanish Ministry of Education and Culture, grant no. PB96-0520. directed by Dr. Francisco Jose Ruiz de Mendoza Ibánez. Correspondence to Sandra Peña Cervel. UNED. Paseo Senda del Rey, 7. Dpto. Filologías Extranjeras y sus Lingüísticas. 28040 Madrid. Tel.: 9139884 69. e-mail: spena@flog.uned.es. 
between metaphors based on the CONTAINER image-schema and those in which such a construct plays no role.

\section{INTRODUCTION}

In contrast to the classical or Aristotelian view, which stigmatizes metaphor as a mere grammatical or rhetorical device, cognitive linguists treat metaphor as a conceptual phenomenon wich pervades both languaje and thought (see the seminal work in Lakoff, 1987, 1989, 1990, 1996; Lakoff \& Johnson, 1980; Lakoff \& Turner, 1989). They account for it in terms of two domains, one of which, the target, which is usually the more abstract, is interpreted in terms of another domain, the source, which tends to be concrete. Even though much of the power of metaphor stems from the fact that source and target belong to different conceptual domains, they share enough properties to make it possible to carry out a straightforward cross-space mapping between them. Researchers such as Kövecses $(1990,1991,1995)$ and Matsuki (1995) have noted that some metaphorical systems are based on abstract spatial constructs, called image-schemas, which can be projected to give structure to a wide variety of cognitive domains (see Johnson, 1987, and Lakoff, 1989 for further discussion). Among the different types of image-schemas one of the most productive ones is the CONTAINER schema, which allows us to envisage and reason about abstract entities in three-dimensional spatial terms. These constructs, which consist on some structural elements plus a basic logic, have been found to lie at the base of a vast array of metaphorical expressions.

Peña (1997) suggests that those emotion metaphors abiding by the internal configuration of the CONTAINER schema may be classified into three main metaphorical systems: PEOPLE ARE CONTAINERS (eg. She was full of joy), ABSTRACT ENTITIES ARE CONTAINERS (eg. She was in low spirits) and EMOTIONS/EMOTIONAL STATES ARE CONTAINERS (eg. He entered a state of euphoria). In this paper, we shall focus on the PEOPLE ARE CONTAINERS metaphor. The analysis of our data reveals that this conceptually basic metaphor can be further specified. Thus, we find some specific metaphors which can be grouped under the heading DIFFERENT (RELEVANT) PARTS OF THE SELF ARE CONTAINERS FOR EMOTIONS. We postulate that this happens as a result of perspectivization (see Taylor, 1989: 90), a process by which we highlight some parts of a given category or entity (for example of a container) and hide or downplay others (see Lakoff \& Johnson, 1980).

In this paper we make use of the cognitive linguistics approach to metaphor in order to study how this idealized cognitive model structures the abstract 
domain of emotions and other related abstract entities by exploiting a number of non-abstract experiences related to body parts. In so doing, it will be evidenced that metaphor proves to be a useful cognitive mechanism in that it endows emotions with a certain kind of conceptual structure. It will also be shown that a large number of emotion metaphors are based on the CONTAINER image-schema (which is given great prominence in the conceptualization of emotions by authors like Kövecses, 1990, 2000), even though there exist others which, being common in ordinary language, do not make use of this cognitive construct.

It has been hypothesized that our perception of the body is a preconceptual structure since it provides the experiential basis for many image-schemas (see Johnson, 1987). In this paper, we shall also suggest that the body and body parts in general constitute structures wich are liable to be conceptualized by means of image-schemas. For instance, our bodies may be inside or outside a given container (eg. I was in love). Additionally, as a structure which can be conceptualized our bodies or any body part can be seen as containers themselves (eg. I was full of joy).

\section{Prototypical body PARTS IN THE CONCEPTUALIZATION OF EMOTIONS}

First of all, we shall analyze those body parts which prototypically serve the metaphorical conceptualization of emotions and other related abstract entities. These are the head, the heart, the bosom, and the breast. In general, the resulting metaphors obey the internal logic of the CONTAINER schema. The emphasis of an expression on a specific body part is a consequence of the process of perspectivization, that is, some specific portion/s of knowledge about containers (or other entities) is/are highlighted and others disregarded ${ }^{2}$. The CONTAINER image-schema consists of an interior, an exterior, and a boundary. Its basic logic is articulated according to the following postulates: everything must be either outside or inside a container; if container $A$ is in container $B$ and $B$ in $C$, then $A$ is inside $C$; boundaries prevent external entities from impinging on what is inside the bounded region; if some entity enters the container, it will affect/be affected either positively or negatively (by) the entity located within the bounded region (see Johnson, 1987; Lakoff, 1987, 1989; Fornés and Ruiz de Mendoza, 1998; Peña, 1997).

${ }^{2}$ This is what Lakoff and Johnson (1980) call the used and unused parts of the metaphor, which roughly corresppond to what Talmy terms windowing of attention and gapping respectively (see Ungerer and Schmid, 1996:233 for further discussion). 


\section{a) THE HEAD IS A CONTAINER FOR EMOTIONALLY LOADED IDEAS}

It may first be observed that the head, rather than a container for emotions, should be understood as a container for ideas which have some kind of emotional load; as a result, the head is seen as a container for emotions only indirectly. Note also that while the head is associated with ideas, the heart is related to emotions. This has an experiential basis. This explains why expressions like His head is full of love/hatred/anger, etc. are not feasible. Nevertheless, we can say that $H$ is head is full of cares/worries/anxieties, etc. because these entities are more easily conceptualizable as ideas than love, which is taken to be the prototypical feeling. All the examples provided below should be interpreted in the light of this observation.

Despite the widespread belief in the rational character of the head, where reason is supposed to be located (see Kövecses, 1990: 179), a set of metaphorical expressions profiles this part of the body as a container for ideas which are emotionally loaded, as can be seen from the following examples:

(1) Her head was full of happy cares.

(2) She has got a big/swollen head.

In (1) the typically negative emotional load which would be associated with cares is overriden by the adjective happy. Swollen head in (2) conventionally refers to excess of pride. In this respect, Kövecses (1990:102) postulates that this expression is but a logical consequence of the metaphorical system $\mathrm{A}$ CENCEITED PERSON IS BIG. However, it may be argued that it is the understanding of the head as a container for ideas which may have some emotional load which provides the basis for this expression. Thus, the size of the head is a consequence of the number of ideas it contains. Any kind of excess inside it may alter or even damage its functionality.

\section{b) THE EYES ARE CONTAINERS FOR EMOTIONS}

The eyes are a functionally prominent part of the head. Much of what we experience and learn - as we say- comes through the eyes. Different eye positions are taken as signs of different emotions. Thus, the eyes become containers for emotions. Furthermore, there exists some experiential basis for this. For instance, when we are angry, our eyes become red or when happy, they become bright: 
(3) There was anger in his eyes

(4) His eyes were full of love

(5) His eyes were overflowing with emotion

(6) I could see the hatred in his eyes

(7) Michael looked at him imploringly, eyes brimming over with tears

(8) Her eyes welled with emotion

(9) His eyes were filled with anger

Now, consider the following metaphorical expressions:

(10) A glitter in the eye

(11) Fire in the eye

(12) Heat in the eye

These metaphors, as cued by the preposition in, are based on the CONTAINER image-schema. However, a closer look at these examples reveals their metonymic basis ${ }^{3}$. Take for instance example 11 . In it, fire is but a subdomain of redness, brightness, heat and other related entities. In this way, fire (the source of the metonymy) is mapped onto the more general domain of redness, brightness, and heat (the target of the metonymy). This is a case of what Ruiz de Mendoza (1999, 2000 ) terms source-in-target metonymies. These metonymies, which constrast with target-in-source ones, give access to a wider domain of reference while target-insource metonymies tend to focus on one component of a given domain. In the metaphor we are dealing with, one of the mappings sets up a correspondence between fire and anger. This metaphor can be represented in the following way:

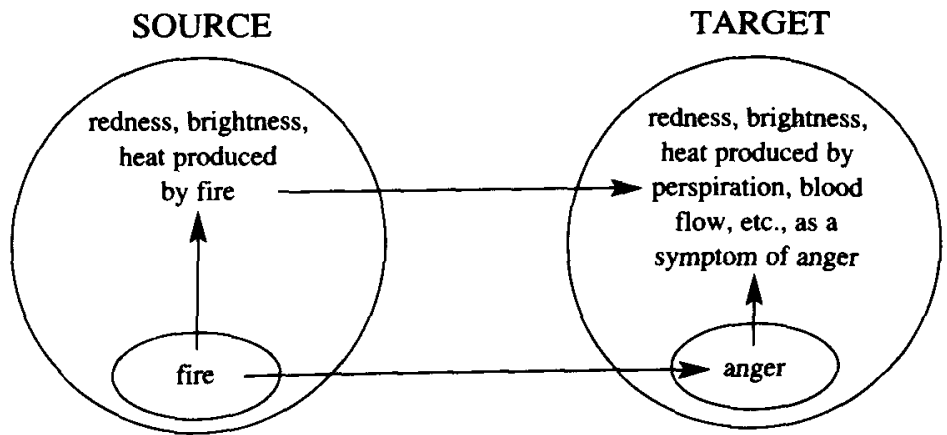

${ }^{3}$ Kövecses had already postulated a metonymic basis for metaphors like ANGER IS HEAT (see Lakoff, 1987). The experiential basis of metaphors like these has led some authors to argue for a possible metonymic grounding for all metaphors (Barcelona 1997, 2000). This is a highly debatable, though plausible, view. In any case, Ruiz de Mendoza's $(1999,2000)$ proposal is fully compatible with it, since source-intarget and target-in-sounce metonymies may have an experiential domain as sounce and target respectively. 
Once a given object (fire) is metaphorically interpreted as an emotion (in this case, anger), we can proceed to regard the eyes as containers for emotions. Making explicit the metonymic grounding of this kind of metaphor allows us to account for its full semantic import.

\section{c) THE HEART IS A CONTAINER FOR EMOTIONS}

The heart is often seen as the place where emotions are located, probably because our experience tells us that when we are sad or worried we feel as if our chests were oppressed but when are happy we tend to adopt an erect posture which makes our chests swell (see Lakoff \& Johnson, 1980). Thus, the same as our bodies, we can think of our hearts as being filled with anger, bitterness, pride, happiness, sorrow, etc.; or they can be empty of emotions, or these may overflow, and so on.

Emotional distress is often expressed in terms of heart trouble. Thus, to have a broken or a bleeding heart is a clear sign of unhappiness. This conceptualization responds to an additional metaphorical mapping whereby happiness is seen as health and life, and sadness as sickness and death (cf. Lakoff \& Johnson, 1980:58).

(13) Her heart swelled with joy and gratitude as she passed the barriers of Portsmouth

(14) Fanny went to bed with her heart as full as on the first evening of her arrival at the Park

(15) Her heart was swelling with emotion

(16) Fanny left the room with a very sorrowful heart

(17) Her heart brimmed over with love and admiration for Charles.

In these expressions the heart is seen as a container for emotions which are in turn conceptualized in the form of a liquid ${ }^{4}$.

\section{d) THE BOSOM IS A CONTAINER FOR EMOTIONS}

According to folk models the bosom, like the heart, is the seat of emotions (see Pauwels \& Simon-Vandenbergen, 1993:343). Furthermore, the understanding

4 The identification of emotions with some kind of liquid is omnipresent in metaphors for emotions. By way of illustration, consider the following examples: Fanny threw her arms round his neck to sob out her various emotions of pain and pleasure... your sentiments, which, unfortunately for himself, he certainly has imbibed; He poured out his hate on us; you come over and pour forth your anger and expect me to take it all in! 
of the bosom as a container has nearly the same experiential grounding as the heart as a container metaphor. As we have observed, when people are happy, they tend to stand upright and as a result the chest becomes bigger (as if swollen). On the other hand, when people are sad or depressed, they tend to adopt a drooping posture and the chest shrinks (see Barcelona, 1986). Now consider these examples:

(18) Her bosom was swollen with pride

(19) His bosom was swollen with joy.

Compare (18) and (19) to She knelt in spirit to her uncle, and her bosom swelled to utter... In this expression, emotions are implicitly invoked, while in the ones above there is explicit mention of such specific emotions as pride and joy. Other things being equal, the mappings which trigger the construal of these metaphors are the same.

Consider the following two expressions:

(20) My little bosom swelled with pride

(21) Pride swelled my little bosom

While (20) is intransitive, (21) is transitive. In both metaphorical expressions, the emotion or object which makes the bosom swell is specified. However, whereas in the first case the logical subject (pride) is demoted to a withcomplement, in the second the logical and grammatical subjects coincide. In (20) the emotion is seen as an instrument by means of which a certain effect- with an experiential basis- is produced. As is the case with non-figurative linguistic expressions including an instrumental case, in (21) we also find the possibility of expressing the instrument as the subject of the clause.

\section{e) THE BREAST IS A CONTAINER FOR EMOTIONS}

Both the bosom and the breast, due to their proximity to the heart, are conceived as the part of the body where the emotions in general are located.

(22) The battle roared; a sound calculated to arouse the sublimest emotions in the breast of the soldier.

The construal of this example is based on the combination of two metaphors: EMOTIONS ARE PEOPLE, which is cued by the verb arouse (it is usually 
people that arouse things), and THE BREAST IS A CONTAINER FOR EMOTIONS, which is invoked by the use of the preposition in. As we can see in this example, in metaphoric interactions the most generic mapping accommodates the least generic ones. In this process, the latter cannot violate the logic of the former in which they become embedded, as evidenced by our example. In it, emotions are seen as people which work inside the soldier's breast thereby affecting it positively.

\section{OTHER LESSS PRODUCTIVE METAPHORS INVOLVING BODY PARTS FOR THE CONCEPTUALIZATION OF EMOTIONS}

Apart from the head, the heart, the bosom, and the breast these exist other body parts which are relevant to the conceptualization of emotions. As was the case with the metaphorical expressions (1) to (23) in the previous section, some metaphors in this section point to the cognitive process of highlighting some portions of a specific event-frame. This is what Taylor (1989:90) and others have termed perspectivization, as remarked above. The metaphors we shall deal with now can be divided into two main subsections:

(i) Those in which the CONTAINER image-schema is involved. These cases, even though the CONTAINER schema plays some role in their conceptualization, are not so productive in the conceptualization of emotions in the English language as the ones we have considered so far.

(ii) Those in which the CONTAINER image-schema plays no role.

Let us consider them in some detail.

\subsection{Other less productive body parts which are relevant to the conceptualization of emotions and in which the container shema is involved}

\section{a) THE BOWELS ARE CONTAINERS FOR EMOTIONS}

Other body parts such as the viscera and bowels, which are located near the gut, are also used in the conceptualization of metaphors for emotions. For instance, we usually refer to feelings as visceral in order to highlight their deep and instinctive character. Thus we can speak about a visceral antipathy or visceral joy. However, the viscera are not seen as containers for emotions from 
a linguistic point of view. On the other hand, the CONTAINER image-schema underlies such metaphorical expressions as to be in the bowels (or depths) of despair. In it, the VERTICALITY schema plays an important role as well. Low locations trigger negative axiological values. However, in our example, this value is reinforced by the experiential grounding of the metaphor A PERSON IS A CONTAINER which here is a dependency of or is triggered by AN EMOTION IS A PERSON (OR ANIMAL). A person's bowels are seen as his/her innermost part from which it is difficult to escape.

\section{b) THE STOMACH IS A CONTAINER}

Another part of the body, located near the bowels, is the stomach. It does not beget a whole metaphorical system of expressions, as is the case with the heart or the head, but it lends further support to the belief that the gut and nearby organs prove relevant to the conceptualization of emotions:

(23) I have butterflies in my stomach.

This metaphorical expression is rather a situational metaphor ${ }^{5}$ in the sense that the tickling effect produced by butterflies is similar to what we feel inside our stomach when nervous. It makes use of the CONTAINER schema, since the stomach is conceptualized as a container which holds some entities: butterflies. This scene conjures up an image of nervousness because of the tickling sensation produced by the movement of these insects. No doubt, nervousness or its effects are not emotions but as has been previously mentioned, we are also concerned with the conceptualization of such other abstract entities as trouble, nervousness, anxiety, and so on.

Now consider this metaphor:

(24) Have food sit badly in one's stomach

This expression is used to mean that someone is sick. In it the conceptualization of food as a person, who is the prototypical agent which sits somewhere, is a

${ }^{5}$ In our view, Ruiz de Mendoza's (personal communication) addition of situational metapphors improves on Lakoff and Johnsson's (1980) distinction aniong structural, urientational, and oncological metaphors. A situational metaphor refers to situations which are conceptualized in terms of other situations. For a detailed analysis of this kind of metaphor (e.g. He got up on his hind legs to defend his views), see Ruiz de Mendoza (2000). 
prerequisite for the interpretation of this metaphor. However, the CONTAINER image-schema is invoked by means of the preposition in. Due to the axiological component of the schema we have just mentioned, if a negative ${ }^{6}$ entity enters a container, such a container will be negatively affected by this entity. In this example, since food is seen as an axiologically negative entity, the individual's stomach will be negatively affected and, as a consequence, he/she is sick.

\section{c) THE SPLEEN IS A CONTAINER FOR EMOTIONS}

Let us add that the spleen, an organ near the stomach which controls the quality of blood, is regarded as a container for emotions (usually for anger) as well:

(25) When I get so frustrated an angry, I have to vent my spleen on someone.

(26) Paul Fussell's latest book vents his spleen against everything he hates about his country.

Observe that a metonymy is the basis for the interpretation of these metaphors ${ }^{7}$. The spleen is a container for an emotion, anger or wrath, and it metonymically stands for the emotion contained in it. The expression to vent one's spleen is understood by virtue of the instantiation of the CONTAINER image-schema. When the emotion in question comes out of the container, the emotion ceases to have an effect on it and consequently on the person.

\subsection{Relevant body parts for the conceptualization of emotions in which the CONTAINER schema plays no role}

a) The gut

The gut is a tube-shaped part of the body located inside the abdomen of a person through which food passes while it is being digested. There do not exist many metaphors which make use of the gut as a specific body part for the

${ }^{\circ}$ In compplying with the postulates of prototype theory (see for instance, Kleiber, 1995), we claim that the terms positive and negative are not absolute but part of a continuum in which there exist more and less positive and negative prototypical values. As a matter of fact, the axiological component depends on other parameters, for example the Control Idealized Cognitive Model.

${ }^{7}$ For the metonymic basis of metaphorical expressions, see Barcelona $(1997,2000)$. 
conceptualization of abstract entities. However, the following example is very common in the English language.

(27) He busted a gut laughing.

This metaphorical expression is also based on experience since our guts contract and expand when we laugh. If the contractions and expansions are very violent they may produce pain or even the breaking of the affected body part. Additionally, the loss of functionality of the affected part, the gut, is profiled in this expression.

\section{b) The side/s}

Even the sides are conceived of as a seat for emotions which are able to be broken:

(28) I split my sides laughing.

This metaphorical expression emphasizes the same experiential basis as the previous metaphor (He busted a gut laughing). When we laugh, our muscles can expand and contract in such a violent way that they can produce pain or the breaking of some part of the body.

Now consider the following expression:

(29) Have a thorn in one's side.

This metaphor is situational in the sense we have described. When a person has a thorn in his/her side, it means that this person is troubled. However, the CONTAINER image-schema underlies this expression as well. A thorn is an object which causes pain. If it is inside a container, such a container will be negatively affected by it. In this case the container is someone's side and a thorn within it makes the whole person feel troubled.

\section{c) The heart}

In the previous section, we argued that the heart is a prototypical body part for the conceptualization of emotions and other related abstract entities. In this section, however, we shall offer some metaphorical examples which, being 
common in ordinary language, are not so prototypical as those we analyzed in section number 1 due to the fact that, as stated by Kövecses (1990), the most prototypical emotion metaphors are those which abide by the logic of the CONTAINER schema. In this connection, consider the following examples:

(30) He was heartbroken/brokenhearted

(31) She was sick at heart/heartsick

(32) She had a heartache when her boyfriend left her

(33) He had an aching heart after they split up.

We might make a twofold distinction between those metaphors in which the heart has been broken and those in which pain is involved. In the first case, the heart is regarded as an object which loses its functionality by being broken or otherwise damaged. On the basis of this observation, we might conclude that it is the metaphorical system A NATURAL OBJECT IS A MAN-MADE OBJECT that licences the interpretation of this kind of expressions. Of course, those metaphors concerning the guts and sides also involve some loss of functionality but, as has been noted, it is mainly their experiential basis that is profiled. On the other hand, those metaphors which make reference to some kind of heartache emphasize the fact that a pain in a certain part of the body is sometimes an indication that such a body part is damaged and may have lost its functionality.

Another set of related examples which should be mentioned is that of situational metaphors involving the heart. They can be subdivided into two main groups: (i) those in which the CONTAINER image-schema is instantiated in some way and (ii) those which do not make use of this schema. By way of illustration, consider the following examples:

(34) Find something in one's heart

(35) Be bankrupt in heart

(36) Feel a dagger plunged in one's heart

(37) Let one's proud heart feed on itself

(38) Feel one's heart pierced

(39) Feel one's heart hammer

(40) Have a heart that has an edge of slivered ice 
In (36), for instance, we have a situational metaphor in which the situation of a dagger plunged somewhere is mapped onto a situation in which a person is so sorrowful that he/she feels as if he/she had been wounded with a dagger. At the same time, the CONTAINER image-schema is cued by means of the preposition in. Since the heart is taken to be the locus of our emotions, it comes as no surprise that it is the place where the dagger is thrown at. Another interesting fact which we have observed in this expression is that the verb plunge usually has a liquid like water as a complement. As we have advanced, EMOTIONS ARE LIQUIDS is a pervasive metaphorical system when talking about the conceptualization of emotions in the English language.

Now consider these examples:

(41) Keep one's heart up

(42) Heart sunk to sudden ashes

(43) Feel a sinking of the heart

These metaphors invoke the VERTICALITY or UP-DOWN image-schema. This cognitive construct is explicit in (41), whereas it is only implicit in (42) and (43). In these examples, whereas high locations (invoked by the preposition $u p$ in 41) trigger positive axiological values, low locations suggest negative axiological values. However, the idea that UP IS GOOD and DOWN IS BAD (originally brought up by Lakoff \& Johnson, 1980, and argued for in length by Krzeszowski, 1993) is only a tendency rather than a rule (cf. Cienki, 1997:4). This is evidenced by expressions like (44):

(44) Feel one's heart leap to one's mouth

This is a situational metaphor in which the VERTICALITY imageschema is implicitly involved. However, the experience of going upwards is not necessarily positive, since this value may be overriden by experiential factors. In (44), the figurative upward movement of the heart may be felt as either positive or negative. It is evident that the experiential grounding of a metaphor provides its strongest, most straightforward link to axiological values.

d) The face

We can also come across examples where we focus our attention on someone's face. Experientially, the emotions are seen as having a visible effect 
on the person's face. Consider the following examples, which respond to different metaphorical systems:

(45) A smile leaves someone's face

(46) His face was radiant with tenderness

(47) One's face falls

Example (45) exploits the PATH image-schema. This schema consists of three structural elements: a starting point, an end point, and a direction. Its basic logic is articulated according to the following postulates: if you go from a source to a destination along a path, then you must pass through each intermediate point of the path and the further along the path you are, the more time has gone by since starting (see Johnson, 1987 and Lakoff, 1987, 1989). Expression (45) involves the PATH image-schema in the sense that the smile is conceptualized as a moving entity which departs from someone's face, which is interpreted as the starting point of a path. A logical entailment of this metaphor is that if the smile leaves the person's face, such a person becomes sad.

Examle (46) is based on the metaphorical systems AN EMOTION IS LIGHT (tenderness in this case) and THE FACE IS A GLOWING OBJECT.

Finally (47) makes use of the VERTICALITY image-schema. In this case DOWN IS BAD, since when someone's face falls, this is a clear sign of disappointment.

\section{CONCLUding REMARKS}

In this paper we have attemped to show that the definition of metaphor as a mapping across domains allows us to give structure to a series of abstract concepts which seemingly have a chaotic structure. With this aim in mind, we have set out to analyze a series of metaphors for emotions and other abstract concepts in which body parts play some role.

We have also made a twofold distinction between those metaphors which make use of the CONTAINER schema and those in which it is not such a construct that provides abstract entities with some kind of structure.

Let us note that except for THE HEAD IS A CONTAINER FOR EMOTIONS the rest of expressions abiding by the internal logic of the metaphorical system DIFFERENT (RELEVANT) PARTS OF THE SELF ARE CONTAINERS FOR EMOTIONS are clustered around two main parts of the body: the head and nearby areas (bosom and breast) and the guts (bowels and even the stomach). This fact is in no way random. It is both grounded in experience and motivated 
by the basic inferences derived from the skeletal conceptual structure of the CONTAINER image-sschema. This does not mean that the CONTAINER schema is the only image-schema that underlies metaphorical expressions involving parts of the body for the expression of emotions. We have observed in our analysis that some of these metaphors obey the basic logic of such other cognitive constructs as the PATH and VERTICALITY schemas. However, our analysis reveals that the CONTAINER image-schema is more prototypical than the others.

\section{REFERENCES}

BARCELONA, A. 1986: «On the concept of depresion in American English: a cognitive aproach», Revista Canaria de Estudios Ingleses, 12: 7-35.

- 1997: «Clarifying and Applying the Notions of Metaphor and Metonymy within Cognitive Linguistics», Atlantis, 19-1, 21-48.

- 2000: «On the plausibility of claiming a metonymic motivation for conceptual metaphor", in Barcelona, A. (ed.), Metonymy and metaphor at the crossroads, Volume in the Topics in English Linguistics series. Berlin: Mouton de Gruyter, 31-58. CIENKI, A. 1997: «Some properties and grouping of image schemas», in Verspoor, M., Dong Lee, K., \& Sweetser, E., (eds.), Lexical and syntactical constructions and the construction of meaning, Amsterdam, Philadelphia: John Benjamins Publishing Company, 3-15.

FoRNEs, M. \& RUIZ DE MENDOZA, F.J. 1998: «Esquemas de imágenes y construcción del espacio", RILCE 14.1, 23-43.

JoHnson, M. 1987: The Body in the Mind: The Bodily Basis of Meaning, Reason, and Imagination. Chicago: University of Chicago Press.

KLeIber, G. 1995. La Semántica de los Prototipos. Madrid: Visor.

KöVECSES, Z. 1986: Metaphors of Anger, Pride, and Love: A lexical Approach to the Structure of Concepts. Amsterdam, Philadelphia: John Benjamins.

- 1990: Emotion Concepts. U.S.A.: Springer-Verlag.

- 1991: «Happiness: a definitional effort», Metaphor and Symbolic Activity, 6.1, 29-46.

- 1995: «The Container Metaphor of Anger in English, Chinese, Japanese, and Hungarian», in Radman, Z. (ed.) From a Metaphorical oint of View: A Multidisciplinary Approach to the Cognitive Content of Metaphor, Berlin, New York: Mouton de Gruyter, 117-145.

KRZESZOWSKI, T.P. 1993: "The axiological parameter in preconceptional image schemata», in Geiger, R.A. \& Rudzka-Ostyn, B., (eds.), Conceptualizations and Mental Processing in Language, Berlin, New York: Mouton de Gruyter, 307-329. 
LAKOFF, G. \& Johnson, M. 1980: Metaphors We Live By. Chicago: Chicago University Press.

- 1999: Philosophy in the Flesh. The embodied Mind and its Challenge to Western Thought. New York: Basic Books.

LAKoff, G. \& TURNer, M. 1989: More than Cool Reason. A Field Guide to Poetic

Metaphor. Chicago \& London: Chicago University Press.

LAKOFF, G. 1987: Women, Fire, and Dangerous Things: What Categories Reveal about the Mind. Chicago: Chicago University Press.

- 1989: «Some empirical results about the nature of conceppts», Mind and Languaje, $4(1 / 2), 103-129$.

- 1990: "The Invariance Hypothesis: is abstract reason based on image-schemas?», Cognitive Linguistics 1-1, 39-74.

- 1996: «Sorry, I'm not myself today: the metaphor system for conceptualizing the Self», in Fauconnier, G. \& Sweetser, E. (eds.), Spaces, Worlds and Grammar. Chicago: Chicago University Press, 91-123.

MATSUKI, K. 1995: «Metaphors of anger in Japanese», in Taylor, J.R. \& MacLaury, R.E. (eds.), Language and the Cognitive Construal of the World, Berlin, New York: Mouton de Gruyter, 137-151.

Pauwels, P. \& Simon-Vandenbergen, A.M. 1993: "Value judgement in the metaphorization of linguistic action», in Geiger, R.A. \& Rudzka-Ostyn, B., (eds.), Conceptualizations and Mental Processing in Language, Berlin, New York: Mouton de Gruyter, 331-367.

PEÑA, S: 1997: «The role of the event structure metaphor and of image-schematic structure in metaphors for happiness and sadness», Miscelánea. A Journal of English and American Studies, 18, 253-266.

RUIZ DE MENDOZA, F.J. 1999: Introducción a la teoría cognitiva de la metonimia. Granada: Granada Linguística y Método Ediciones.

- 2000: "The role of mappings and domains in understanding metonymy" in Barcelona, A. (ed.), Metonymy and Metaphor at the Crossroads, Volume in the Topics in English Linguistics Series, Berlin: Mouton de Gruyter, 109-132.

TAYLOR, J.R. 1989: Linguistic Categorization. Prototypes in Liguistic Theory. Oxford: Clarendon Paperbacks.

UNGERER, F. \& SCHMID, H.J. 1996: An Introduction to Cognitive Linguistics. New York, London: Longman. 